\title{
Seismic Responses of NPP Structures Considering the Effects of Lead Rubber Bearing
}

\author{
Duy-Duan Nguyen \\ Department of Civil Engineering \\ Vinh University \\ Vinh, Vietnam \\ duyduankxd@vinhuni.edu.vn
}

\author{
Can-Ngon Nguyen \\ Department of Civil Engineering \\ Vinh University \\ Vinh, Vietnam \\ canngonkxd@vinhuni.edu.vn
}

\begin{abstract}
This study investigates the effects of Lead Rubber Bearings (LRBs) on Floor Response Spectra (FRS) of Nuclear Power Plant (NPP) structures. Three main structures in the Advanced Power Reactor 1400 (APR1400) NPP including the reactor containment building, an internal structure, and an auxiliary building were numerically developed in SAP2000. The structures were modeled using beam stick elements, and lumped masses were assigned to beam element nodes. All equivalent section properties of beam elements were calculated based on the designed cross-sections of the structures. A series of $\mathbf{4 0}$ ground motions with response spectra scaled to match the NRC 1.60 spectrum were utilized in numerical time-history analyses. Finally, a thorough comparison of FRS was conducted at different elevations of the structures, considering both with and without LRB. Numerical results showed that the FRS of baseisolated structures at higher elevations was significantly reduced compared to non-isolated structures. However, at lower elevations, the FRS was higher for the base-isolated structures compared to the non-isolated ones. Additionally, at a lowfrequency range, roughly smaller than $3 \mathrm{~Hz}$, the FRS of baseisolated structures was always greater than that of the nonisolated ones.
\end{abstract}

Keywords-nuclear power plant; lumped mass stick model; floor response spectrum; lead rubber bearing

\section{INTRODUCTION}

Recent earthquakes such as the 2011 Tohoku earthquakes in Japan and the 2011 Mineral Virginia earthquakes in USA harmed the Nuclear Power Plants (NPPs) in these regions. The 2016 Gyeongju and the 2017 Pohang earthquakes in South Korea struck close to the nearby NPPs showing that peak ground acceleration can be larger than the design level of NPPs. Therefore, more studies on the seismic performance of NPP structures are needed. Base isolators such as Lead Rubber Bearing (LRB) or friction pendulum systems can mitigate the possibility of damage to the civil structures and NPPs during an earthquake [1-4]. Numerous studies have been conducted on the effects of base isolators and the seismic performance of base-isolated NPP structures. The effects of the variability of properties of LRB were evaluated in [5], including the material variability in manufacturing, aging, and the operational temperature effects on the response of a base-isolated NPP structure. Authors in [6] analyzed the vertical seismic response of based-isolated NPP structures using LRBs, comparing the maximum accelerations at the top of the structures and the specific positions between fixed and various LRB models. In [7], the effect of the second hardening of Bouc-Wen model was investigated for LRB on FRS of a base-isolated NPP. Authors in [8] compared the seismic response of seismically isolated NPP containment structures using equivalent linear- and nonlinear-lead-rubber bearing models. Moreover they quantified the seismic responses, including displacement and shear force, between non-isolated and base-isolated systems. The effect of the mechanical properties of LRB on FRS of NPP structures was investigated in [9], measuring FRS only at the top of the structures. The FRS of a seismically base-isolated NPP and a comparison between FRS at the top of the structure between non- and base-isolated models was analyzed in [10]. However, the aforementioned works did not sufficiently compare FRS at various elevations of NPP structures, where the equipment and devices are possibly located, considering with and without LRB.

This study investigates the effect of LRB on FRS of NPP structures. Three main structures in APR1400 NPP including the reactor containment building, internal structure, and auxiliary building were modeled. A series of 40 ground motions with response spectra scaled to match the NRC 1.60 spectrum [12] were utilized in numerical analysis. A thorough comparison of FRS at various elevations of the structures was conducted, considering both with and without base isolator.

\section{GROUND MOTIONS}

This study selected 40 ground motion records from worldwide earthquakes provided by the PEER center [11], and scaled to match the US NRC 1.60 design spectrum [12]. The compatible matching spectra were generated using the SeismoMatch tool. Figure 1 shows the response spectra of input ground motions and the NRC 1.60 spectrum.

\section{NUMERICAL MODELING}

The ARP1400 NPP was employed as an example, focusing on the Reactor Containment Building (RCB), the Internal Structure (IS), and the Auxiliary Building (AB). The NPP structures were modeled in terms of a lumped-mass stick model using elastic beam elements in SAP2000 [13], as shown in Figure 2. All equivalent section properties were calculated 
based on the structures' design cross sections. The lumped masses were also assigned to associated element nodes. Elastic shell elements were applied for the base-mat foundation. Figure 3 shows the based-isolated model and the arrangement of LRBs. More details of the modeling can be found in [14-19].

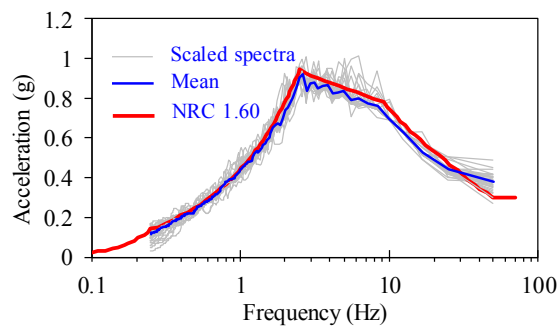

Fig. 1. Response spectra of ground motions.

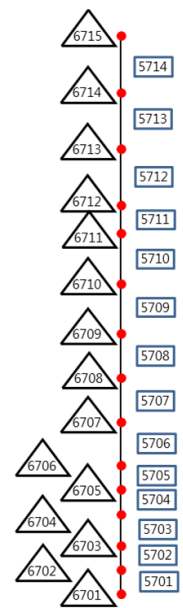

(a) $\mathrm{RCB}$

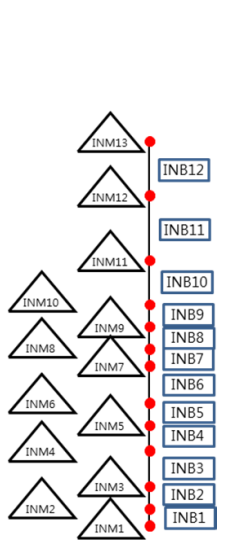

(b) IS

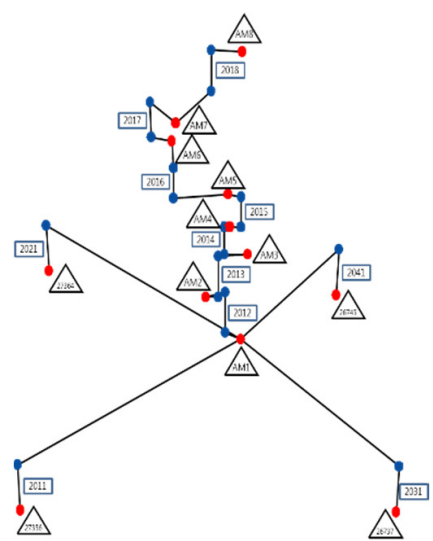

(c) $\mathrm{AB}$

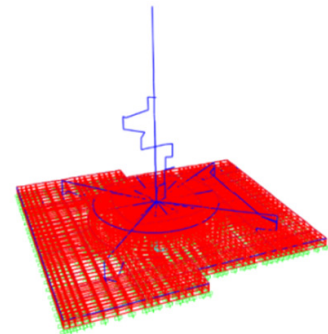

(d) Complete finite element model of NPP structure

Fig. 2. Lumped-mass stick model of the NPP structures.

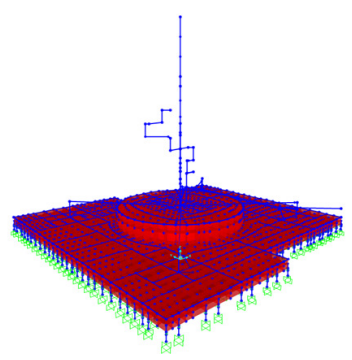

(a) base-isolated NPP model

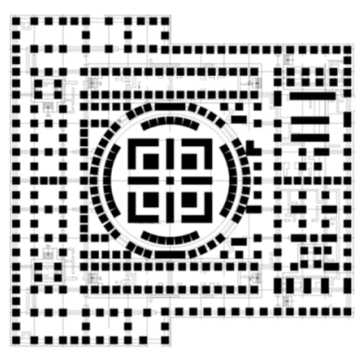

(b) arrangement of $468 \mathrm{LRBs}$

Fig. 3. Base-isolated NPP model and arrangement of LRBs.

The 1 st and 2 nd modes of the non-isolated NPP model are the horizontal translation modes of the containment building, while the $3 \mathrm{rd}$ and 4 th modes represent the translational modes of the auxiliary building, as shown in Figure 5(a). For the baseisolated NPP model, the 1st and 2nd modes are translational modes of the superstructure, the 3rd mode represents the rotational mode, and the 4th mode is the translational model of the containment building, as shown in Figure 5(b).

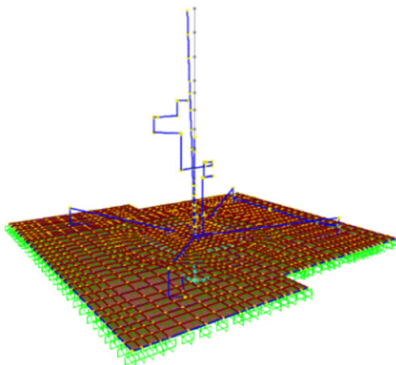

(a) Mode $1, \mathrm{~T} 1=3.858 \mathrm{~s}$

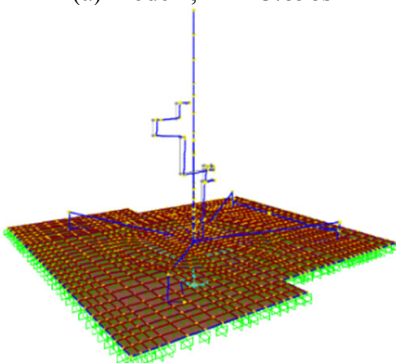

(c) Mode 3, T3 $=5.077 \mathrm{~s}$

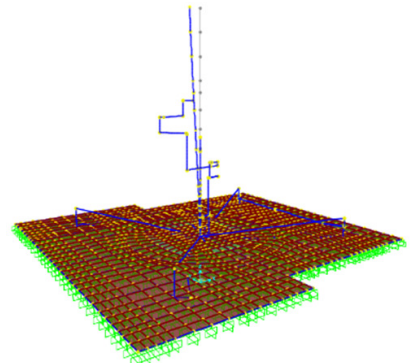

(b) Mode 2, T2 $=3.859 \mathrm{~s}$

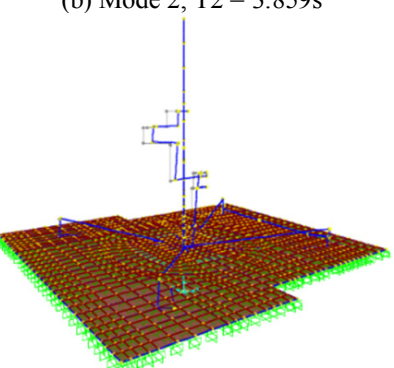

(d) Mode 4, T4 $=5.351 \mathrm{~s}$
Fig. 4. Modal analysis results of non-isolated NPP

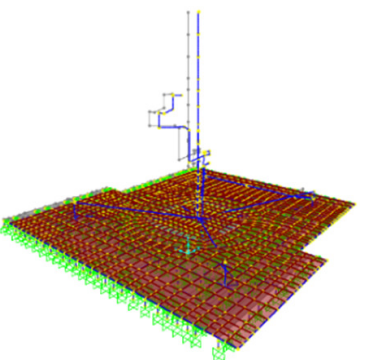

(a) Mode $1, \mathrm{~T} 1=0.476 \mathrm{~s}$

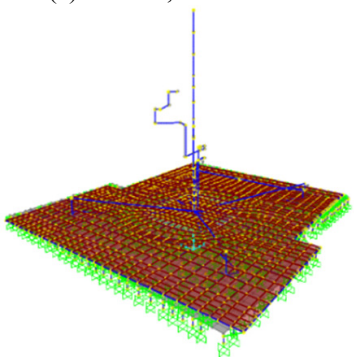

(c) Mode 3, T3 $=0.709 \mathrm{~s}$

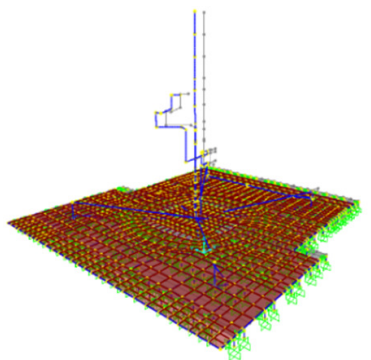

(b) Mode 2, T2 $=0.477 \mathrm{~s}$

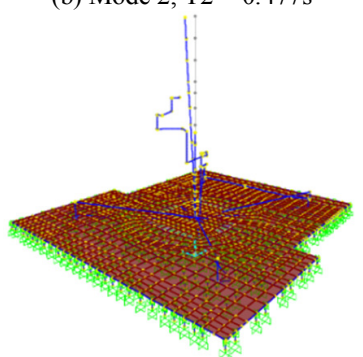

(d) Mode 4, T4 $=3.786 \mathrm{~s}$
Fig. 5. Modal analysis results of base-isolated NPP.

\section{FLOOR RESPONSE SPECTRA}

A series of linear time-history analyses were performed since NPP structures are expected to vibrate within an elastic 
range during an earthquake. All ground motions were imposed on the NPP models in horizontal direction. Normally, the lateral acceleration or displacement responses of structures are monitored during earthquakes [20-22]. The seismic response of both non- and base-isolated NPP structures was obtained in terms of the FRS. FRS was monitored at different elevations of $\mathrm{RCB}$, IS, and $\mathrm{AB}$, as floor accelerations of the primary structures are input loadings to the attached secondary components, such as mechanical devices, electrical equipment or relays, piping systems, and other machines in NPPs [23].

Figure 6 shows the FRS of RCB at various elevations considering the cases with and without base isolators. The thin gray curves represent all ground motion results, while the red curve is the mean spectrum. The non-isolated model's FRS at lower elevations not only amplified at the fundamental frequency (i.e. $3.9 \mathrm{~Hz}$ ), but also at a higher frequency, approximately $10.2 \mathrm{~Hz}$. However, at higher elevations, FRS of the RCB purely magnified at the fundamental frequency. The base-isolated model's FRS of RCB was amplified at a wide range of frequency approximately from 2.5 to $9.0 \mathrm{~Hz}$ at lower elevation. As the elevation increased, FRS was only amplified at the fundamental frequency of RCB (i.e. $3.8 \mathrm{~Hz}$ ).
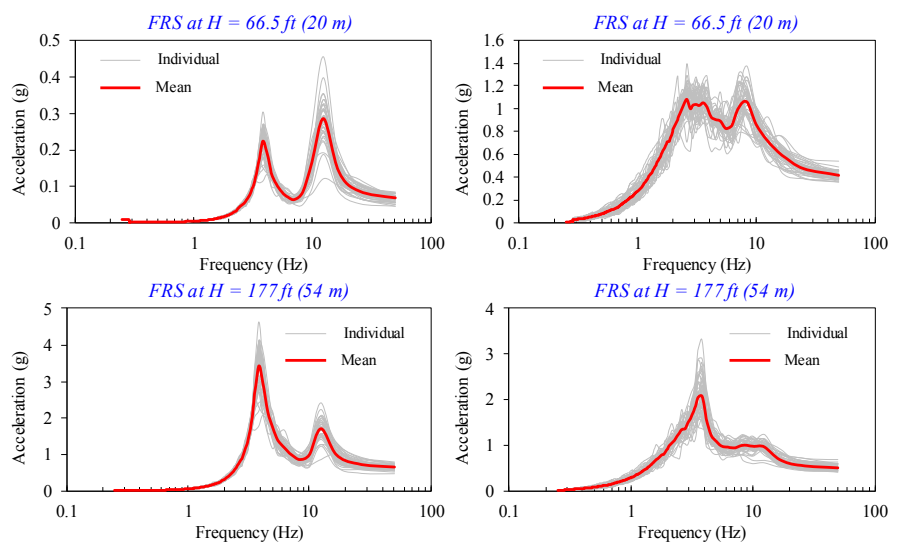

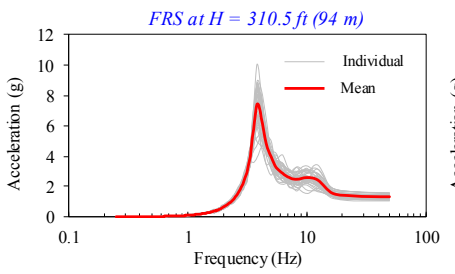

(a) Non-isolated model

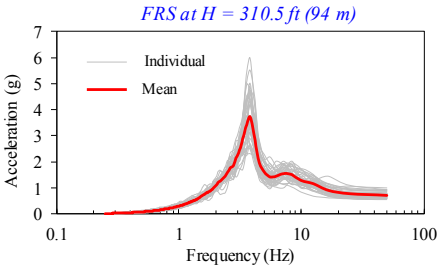

(b) Base-isolated model
Fig. 6. FRS of RCB with and without LRB.

Figure 7 shows the comparison of mean FRS of RCB at different elevations for both non- and base-isolated models. It is obvious that FRS was increased from lower to higher elevations of RCB. FRS of non-isolated RCB was double amplified at the top node compared to the base-isolated model, as LRB dissipates the input energy and therefore the inertial forces are reduced in the base-isolated structure. Figure 8 shows the FRS comparisons for each elevation with and without LRB. At lower elevations, the FRS of the base-isolated $\mathrm{RCB}$ is higher than the non-isolated model. This is attributed to the fact that the induced acceleration is always zero at the base of the fix-based model, while the accelerations along the height are distributed in a triangular shape. Meanwhile, the baseisolated model has non-zero acceleration at the base, and it is gradually increasing along the height of the structure. These observed behaviors are consistent with the findings of [10]. It should be noted that the FRS of base-isolated RCB showed to be larger than those of the non-isolated structure in a lowfrequency range, smaller than $3.0 \mathrm{~Hz}$, due to the smaller fundamental frequency of the isolated model, and therefore the FRS of the base-isolated structure is amplified at the lower frequency region. These trends were also observed for IS and AB.

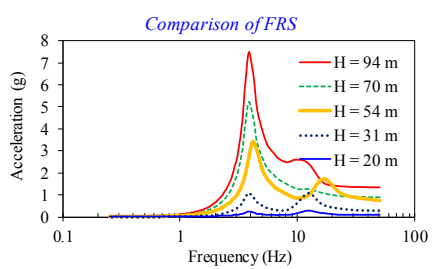

(a) Non-isolated model

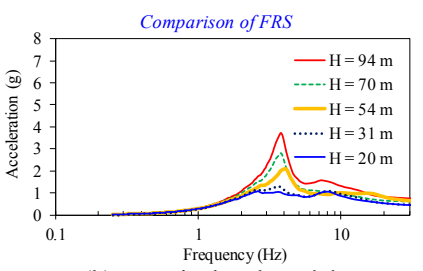

(b) Base-isolated model
Fig. 7. Comparison of FRS of RCB in various elevations.
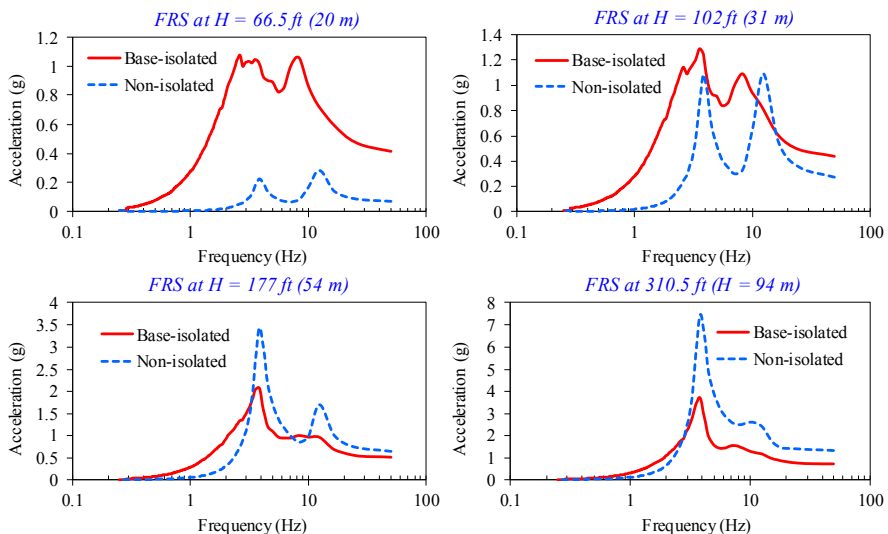

Fig. 8. Comparison of FRS of RCB with and without LRB.

\section{CONCLUSION}

This study conducted a series of time-history analyses to obtain the FRS at different elevations of RCB, IS, and AB in the APR1400 NPP. The effect of LRB on FRS was considered by comparing the FRSs between a non-isolated and a baseisolated model. A set of 40 ground motions with response spectra matching the US NRC 1.60 spectrum was used. The following conclusions were drawn based on numerical analysis results.

- As elevation increases, the FRS of non-isolated structures is dramatically amplified. The FRS at the top of the nonisolated structures is about 2-3 times larger than in baseisolated structures.

- In NPP structures with LRB, the FRS at higher elevation is significantly reduced compared to the non-isolated structures. However, at lower elevation, the FRS is higher for base-isolated structures compared to non-isolated. 
- At low frequency range, roughly smaller than $3 \mathrm{~Hz}$, the FRS of base-isolated structures is always larger than in nonisolated.

- At the frequency of $12.1 \mathrm{~Hz}$, the spectral acceleration of the base-isolated $\mathrm{AB}$ at various elevations is smaller than in non-isolated $\mathrm{AB}$.

\section{REFERENCES}

[1] T. H. Lee and D.-D. Nguyen, "Seismic vulnerability assessment of a continuous steel box girder bridge considering influence of LRB properties," Sādhanā, vol. 43, no. 1, p. 14, Feb. 2018, https://doi.org/ 10.1007/s12046-017-0774-x.

[2] S. Eem and D. Hahm, "Large strain nonlinear model of lead rubber bearings for beyond design basis earthquakes," Nuclear Engineering and Technology, vol. 51, no. 2, pp. 600-606, Apr. 2019, https://doi.org/ 10.1016/j.net.2018.11.001.

[3] J. H. Lee and J.-K. Song, "Seismic Fragility Analysis of Seismically Isolated Nuclear Power Plant Structures using Equivalent Linear- and Bilinear-Lead Rubber Bearing Model," Journal of the Earthquake Engineering Society of Korea, vol. 19, no. 5, pp. 207-217, 2015, https://doi.org/10.5000/EESK.2015.19.5.207.

[4] J. S. Kim, J. P. Jung, J.-H. Moon, T.-H. Lee, J. H. Kim, and T.-S. Han, "Seismic Fragility Analysis of Base-Isolated LNG Storage Tank for Selecting Optimum Friction Material of Friction Pendulum System," Journal of Earthquake and Tsunami, vol. 13, no. 2, p. 1950010, Apr. 2019, https://doi.org/10.1142/S1793431119500106.

[5] Y. S. Choun, J. Park, and I.-K. Choi, "Effects of Mechanical Property Variability in Lead Rubber Bearings on the Response of Seismic Isolation System for Different Ground Motions," Nuclear Engineering and Technology, vol. 46, no. 5, pp. 605-618, Oct. 2014, https://doi.org/10.5516/NET.09.2014.718.

[6] S. G. Cho, S. M. Yun, D. Kim, and K. J. Hoo, "Analyses of Vertical Seismic Responses of Seismically Isolated Nuclear Power Plant Structures Supported by Lead Rubber Bearings," Journal of the Earthquake Engineering Society of Korea, vol. 19, no. 3, pp. 133-143, 2015, https://doi.org/ 10.5000/EESK.2015.19.3.133.

[7] J. W. Jung, H. W. Jang, J. H. Kim, and J.-W. Hong, "Effect of second hardening on floor response spectrum of a base-isolated nuclear power plant," Nuclear Engineering and Design, vol. 322, pp. 138-147, Oct. 2017, https://doi.org/10.1016/j.nucengdes.2017.06.004.

[8] J. H. Lee and J.-K. Song, "Comparison of Seismic Responses of Seismically Isolated NPP Containment Structures using Equivalent Linear- and Nonlinear-Lead-Rubber Bearing Modeling, " Journal of the Earthquake Engineering Society of Korea, vol. 19, no. 1, pp. 1-11, 2015, https://doi.org/10.5000/EESK.2015.19.1.001.

[9] D. D. Nguyen, B. Thusa, H. Park, H. Lee, and T. H. Lee "Effects of mechanical properties of LRB on seismic performance of base-isolated NPP structures," presented at the Transactions of the $25^{\text {th }}$ Structural Mechanics in Reactor Technology (SMiRT-25), Charlotte, NC, USA, Aug. 4-9, 2019.

[10] J. Wong and S. Mahin, "Primary analysis of floor response spectra of a seismically base isolated nuclear power plant," presented at the Transaction of the $22^{\text {th }}$ Structural Mechanics in Reactor Technology (SMiRT-22) Conference, San Francisco, CA, USA, Aug. 18-23, 2013.

[11] PEER Strong Ground Motion Databases, Pacific Earthquake Engineering Research Center, 2019. [Online]. Available: http://peer.berkeley.edu/peer_ground_motion_database

[12] Design response spectra for seismic design of nuclear power plants, 1.60 , U.S. Nuclear Regulatory Commision, Revision 2, Rockville, Maryland, USA, Jul. 2014.

[13] SAP2000 (2015), Computers and Structures Inc. [Online]. Available: https://www.csiamerica.com/products/sap2000

[14] D. D. Nguyen, B. Thusa, and T. H. Lee, "Seismic Fragility of BaseIsolated Nuclear Power Plant Considering Effects of Near-Fault Ground Motions," Journal of the Korean Society of Hazard Mitigation, vol. 18, no. 7, pp. 315-321, Dec. 2018, https://doi.org/10.9798/KOSHAM. 2018.18.7.315

[15] D. D. Nguyen, B. Thusa, and T. H. Lee, "Effects of Significant Duration of Ground Motions on Seismic Responses of Base-Isolated Nuclear Power Plants," Journal of the Earthquake Engineering Society of Korea, vol. 23, no. 3, pp. 149-157, 2019, https://doi.org/10.5000/ EESK.2019.23.3.149.

[16] B. Thusa, D.-D. Nguyen, H. Park, and T.-H. Lee, "Seismic Response Evaluation of NPP Structures Considering Different Numerical Models and Frequency Contents of Earthquakes," Journal of the Computational Structural Engineering Institute of Korea, vol. 33, no. 1, pp. 63-72, 2020, https://doi.org/10.7734/COSEIK.2020.33.1.63.

[17] D.-D. Nguyen, B. Thusa, T.-S. Han, and T.-H. Lee, "Identifying significant earthquake intensity measures for evaluating seismic damage and fragility of nuclear power plant structures," Nuclear Engineering and Technology, vol. 52, no. 1, pp. 192-205, Jan. 2020, https://doi.org/ 10.1016/j.net.2019.06.013.

[18] A. Ali, N. A. Hayah, D. Kim, and S. G. Cho, "Probabilistic seismic assessment of base-isolated NPPs subjected to strong ground motions of Tohoku earthquake," Nuclear Engineering and Technology, vol. 46, no. 5, pp. 699-706, Oct. 2014, https://doi.org/10.5516/NET.09.2014.030.

[19] D. Van Nguyen, D. Kim, and D. Duy Nguyen, "Nonlinear seismic soilstructure interaction analysis of nuclear reactor building considering the effect of earthquake frequency content," Structures, vol. 26, pp. 901914, Aug. 2020, https://doi.org/10.1016/j.istruc.2020.05.013.

[20] J. A. Alomari, "Effect of the Presence of Basements on the Vibration Period and Other Seismic Responses of R.C. Frames," Engineering, Technology \& Applied Science Research, vol. 9, no. 5, pp. 4712-4717, Oct. 2019, https://doi.org/10.48084/etasr.3005.

[21] T. Nagao, "An Experimental Study on the Way Bottom Widening of Pier Foundations Affects Seismic Resistance," Engineering, Technology \& Applied Science Research, vol. 10, no. 3, pp. 5713-5718, Jun. 2020, https://doi.org/10.48084/etasr.3590.

[22] P. C. Nguyen, B. Le-Van, and S. D. T. V. Thanh, "Nonlinear Inelastic Analysis of 2D Steel Frames :," Engineering, Technology \& Applied Science Research, vol. 10, no. 4, pp. 5974-5978, Aug. 2020, https://doi.org/10.48084/etasr.3600.

[23] H. S. Park, D.-D. Nguyen, and T. H. Lee, "Effect of High-frequency Ground Motions on the Response of NPP Components: A State-of-theart Review," Journal of the Korean Society of Hazard Mitigation, vol. 17, no. 6, pp. 285-294, Dec. 2017, https://doi.org/10.9798/ KOSHAM.2017.17.6.285. 